\begin{tabular}{lc}
\hline SCIENCE \& TECHNOLOGY \\
Journal homepage: http://www.pertanika.upm.edu.my/ \\
\hline PERTANIKA
\end{tabular}

\title{
Development of Pulp Moulded Packaging Samples from Empty Fruit Bunch Fibre
}

\section{Qiuyun Liu'* , Ceri Loxton', Amir Alzahari Mohamed², Mohammad Jawaid ${ }^{3}$, Radek Braganca $^{1}$ and Robert Elias ${ }^{1}$}

${ }^{1}$ The Biocomposites Centre, Bangor University, Bangor, Gwynedd, LL57 2UW, UK

${ }^{2}$ Eco Premium Packaging, 71800 Nilai, Negeri Sembilan, Malaysia

${ }^{3}$ Laboratory of Biocomposite Technology, INTROP, Universiti Putra Malaysia,

43400 UPM Serdang, Selangor, Malaysia

\begin{abstract}
Single-use plastic packaging is a cause of rising environmental concerns due to high production volumes, short usage time, and problems related to end of life management and release into the environment. As a result, there is an increased demand to develop alternative non-plastic packaging from agricultural waste materials. This paper reported findings for converting, via atmospheric refining, waste oil palm empty fruit bunch (EFB) fibres into a fibrous pulp which can then be used to produce three-dimensional pulp moulded products. By optimising the mould design, the efficiency of vacuum suction was improved, which in turn helped to improve fibre distribution and the quality of moulded trays; such moulded trays are suitable for the containment of food items such as fruit and vegetables. Furthermore, when combined with compostable barrier treatments, lidding and adhesive films currently under development, there is an opportunity to provide a complete biocompostable packaging solution for some food items. Furthermore, as these pulp moulded packaging products are made from agricultural fibre wastes rather than plastics, the pulp moulded trays are recyclable or compostable at the end of life. Therefore, if a

ARTICLE INFO

Article history:

Received: 11 May 2021

Accepted: 27 July 2021

Published: 22 October 2021

DOI: https://doi.org/10.47836/pjst.29.4.36

$\overline{\text { E-mail addresses: }}$

q.liu@bangor.ac.uk (Qiuyun Liu)

c.loxton@bangor.ac.uk (Ceri Loxton)

amiralzahari@gmail.com (Amir Alzahari Mohamed)

jawaid@upm.edu.my (Mohammad Jawaid)

r.braganca@bangor.ac.uk (Radek Braganca)

r.m.elias@bangor.ac.uk (Robert Elias)

* Corresponding author

release does occur into the environment, it would not persist.

Keywords: Empty fruit bunch, packaging, pulp moulding, trays

INTRODUCTION

Plastic packaging represented $36 \%$ of global plastic production in 2015 (Geyer et al., 2017). However, Geyer et al. (2017)
\end{abstract}


estimate that just $9 \%$ of all plastic ever produced has been recycled, $12 \%$ has been incinerated, but the remaining 79\% has either been landfill, dumped or ended up as litter in the environment.

Growing public and governmental concerns around plastic packaging, particularly single-use plastics, have led to more than 60 countries introducing regulations to limit the use of plastic bags and Styrofoam products (UNEP, 2018). In Europe, there has been increased interest in alternatives to single-use plastic packaging following various high profile news items about the 'ocean of plastic' and the banning of waste plastic imports by China (Cole, 2017). In the UK, a number of supermarkets have announced that they are phasing out plastic from their packaging (Laville \& Smithers, 2018), while the world's first plastic-free shopping aisle opened in the Netherlands in 2018 (Taylor, 2018).

These measures are predicted to be a step towards other policies aimed at reducing plastic waste by replacement with more sustainable, environmentally friendly alternatives. Furthermore, bans on the use of plastic and growing governmental and customer concerns around single-use plastics are resulting in opportunities for the introduction of marketing innovative, environmentally sound alternatives (UNEP, 2018) and have led to a growing interest in packaging alternatives (Porter, 2018).

In Europe, demand for paper-based packaging now represents more than half of European packaging production. Pulp moulded products (PMPs) are one such alternative to plastic packaging. They have been gaining rapid commercial importance over recent years as companies look for alternatives to plastic-based packing; the demand increases due to their sustainability qualities (Wever \& Twede, 2007). Initially, PMPs were associated with egg packaging and fruit trays (dry foods). However, they are now finding applications as "food containers, clinical waste healthcare products, and packaging for electronic goods" (Didone et al., 2017). PMPs are usually made from a wood fibre-based raw material, often derived from recycled paper/card. Depending on the source of that recycled material the resulting pulp may or may not be suitable for packaging material that will come into contact with food.

Different grades of recovered/recycled paper and board are available. More than 50 grades are defined in the European List of Standard Grades of Recovered Paper and Board as per EN643. These grades can be categorised (Didone et al., 2017) into three principal groups: low grades, de-inking grades and high grades. The high grades originate mainly from within manufacturing environments-so offcuts from sheets or print run. The de-inking grade originates primarily from newspaper and magazine material and is not suitable for direct contact with food. This grade is also considered to be a low grade because of the extensive deinking that is required. The bulk of recovered paper falls into the 'low' grade category and comprises mixed papers, old corrugated containers and boxes. This low grade recycled material is mainly destined for secondary packaging applications. 
Unfortunately, only some grades of recycled paper are considered suitable for use as food packaging. The majority are not due to possible contamination. The principal contaminants in paper and board products are derived from dyes, printing inks and lacquers, adhesives, sizing and coating agents; however, there may also be dispersants used at the de-inking stage during recycling (Bengström, 2014). Mineral oil hydrocarbons, derived from printing inks, were of particular concern in the 1990s and onwards, leading to new legislation to minimise migration of mineral oils from boxes of recycled paperboard to dry food. However, this legislation is still to be fully enforced (Grob, 2018). Nevertheless, it is one reason for interest in finding alternative fibre sources from which to make PMPs. 'Waste' agricultural fibres may be able to provide suitable quality fibre that has not been contaminated with dyes and inks from recycled papers.

Once the pulp has been prepared, the next step in the manufacturing process of pulp moulded products involves vacuum-forming the pulp slurry (fibres mixed with water) over a wire forming mesh into the desired shape. Water drains from the pulp through the wire mesh, leaving a wet formed shape from which additional water is then removed by the application of pressure and or heat and pressure. The resulting three-dimensional product can be classified in a number of different ways according to density and fabrication method. The classification that has been accepted by the International Moulded Fibre Association (National Agricultural Library, 2014) lists four main categories of PMPs, these being thickwalled (5 to $10 \mathrm{~mm}$ ), transfer moulded ( 3 to $5 \mathrm{~mm}$ wall thickness), thermoformed (with hot-pressed, densified walls of 0.8 to $1.2 \mathrm{~mm}$ in thickness). The fourth general category is 'processed'. The processed category covers any moulded product that has undergone further treatment, such as the addition of paint, coatings, or additives.

Non-wood fibres such as sugar cane, bagasse and various cereal straws, flax and hemp are being used to manufacture paper (Zhaohua et al., 1998; Hammet et al. 2001) and thus are likely to find their way into recycled paper streams and so into pulp moulded products. However, to date, little work has been published in the area of directly substituting woodbased pulps for non-wood fibre pulps in pulp moulded products. Curling et al. (2017) looked at the feasibility of substituting pure Kraft pulp, which is relatively expensive, with cereal straw and successfully up to $80 \%$ substitution. However, they could not make a product from $100 \%$ wheat straw (Triticum aestirum cv Solstice) due to poor wet strength preventing removal of the product from the mould. Kim et al. (2016) reported an addition of empty fruit bunch fibres to pulp made from old newspaper to help improve properties with changes to bulk density improving drainage. Hamouda et al. (2019) reported fabricating hybrid composite materials using Tetra Pak package waste reinforced with waste wool fibres for packaging applications.

While the pulp moulding industry is generally well established around recycled paper and existing supply chains (mainly wood-based raw materials), there is a growing interest in 
looking at alternative fibre sources. There are a number of traditional drivers for looking at non-wood pulps, supply, cost, availability, fibre characteristics, sustainability and increased interest in the circular economy (Geueke et al., 2018).

The oil palm (Elaeis guineensis) industry in Malaysia generates much waste; for every 5.5 , tonnes of oil produced 55 tonnes of dry fibrous biomass is left behind (Or et al., 2017). Among the various dry fibrous biomass from an oil palm tree, empty fruit bunch account for up to $73 \%$ of this fibrous biomass. Hamzah et al. (2019) reported that in 2017, 22.2 million tonnes of EFB was produced-which normally ends up being incinerated or applied to fields. This research project aimed to establish if EFB would be a suitable raw material for pulp moulded products.

Empty fruit bunch fibre can be pulped using various chemical, semi-chemical or thermomechanical pulping methods (Ferrer et al., 2011). Chemical and semi-chemical processing are preferable where high-quality pulp is required. Ibrahim et al. (2007) reported on the successful production, at a commercial scale, of paper from EFB using soda pulping. This paper will report findings for converting, via atmospheric refining, the waste material of EFB fibres into a fibrous pulp which was then used to produce pulp moulded product samples in the development of compostable barrier treatments lidding and adhesive films.

\section{MATERIALS AND METHODS}

\section{Raw Materials}

Empty fruit bunch fibre (EFB) was supplied by Eco Premium Packaging from Malaysia and sent to The BioComposites Centre at Bangor University in the UK. The control material was recycled cardboard (without ink) collected in the UK.

\section{Atmospheric Refining of EFB Fibres}

The length of EFB fibre was reduced by first chopping the long fibre bundles to approximately $5 \mathrm{~cm}$ in length using a Pierret B6838 Corbion. The fibre length is achieved by adjusting the speed of the feed rollers. It was required to ensure that the material would transfer through the screw feeder to the refining zone of the laboratory 12" Sprout Waldron single atmospheric disc refiner. The diameter of the screw feeder was $100 \mathrm{~mm}$. The chopped EFB fibres were soaked overnight in water at room temperature prior to refining, as shown in Figure 1(a).

The EFB/water mix was poured into the feed hopper of the atmospheric refiner. Care was needed to distribute the EFB evenly to avoid clumping the material as it entered the screw feeder, as this could lead to blockages. Target consistency for this stage was $4 \%$. Two experimental pulps were produced, one from material that had passed through the refining zone three times ("3 Pass"), with the plate gap being reduced on each subsequent 
pass. The starting plate gap was $25 / 1000$, followed by plate gaps of 10 and 5/1000". This pulp was then split into half and one portion was passed through the refiner for a fourth time (“4 Pass") at a smaller plate gap of 3/1000". Refined EFB after 3 passes is shown in Figure 1(b). A reduction in fibre length ( 3 to $5 \mathrm{~mm}$ ) was visible by the eye.

\section{Hand Sheets}

Information gathered from test handsheets is widely used in the paper industry as an indication of pulp quality and a measure of the potential contribution of the pulp to the strength of the finished paper product (Kibblewhite et al., 2000). Whilst not strictly designed for pulp moulded products, the same approach can be used to assess the properties of the pulps and products. In this case, the handsheet making procedure was based on TAPPI Method T 205 (TAPPI TEST Methods, 1994a). The method involved disintegration at a consistency of $2.5 \%$ (corresponding to $50 \mathrm{~g}$ of material in a total volume of 2 litres); sheet making at a consistency of $1.5 \%$; couching (standard couch roll and plate), and laying

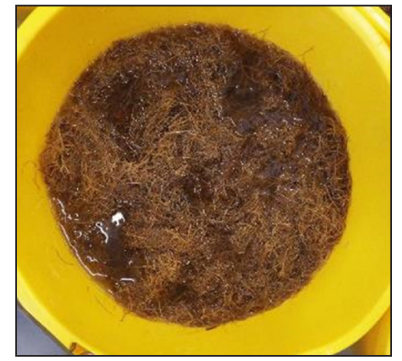

(a)

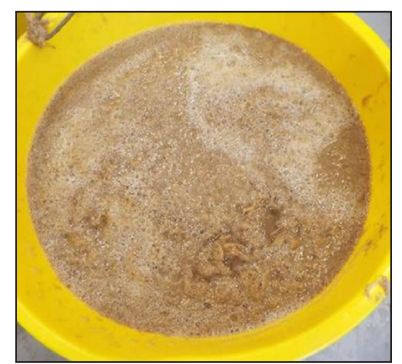

(b)

Figure 1. EFB fibres before the refining with fibre length at $5 \mathrm{~cm}$ (a) and fibre length reduced to 3 to $5 \mathrm{~mm}$ after the refining (b) in a press (first and second pressing) and finally drying (using mirror-polished discs in $160 \mathrm{~mm}$ diameter with rubber seatings for holding the sheets to the polished discs during drying). Ten standard sheets $(159 \mathrm{~mm}$ in diameter) from the 4 refiner passes formulation and recycled cardboard was made successfully with a target weight of $1.2 \mathrm{~g}$ (oven-dry weight) per sheet and tested. However, handsheets from 3 refiner passes EFB fibres could not be removed from the couching plate. Therefore, no handsheets were made from this formulation.

\section{Handsheet Testing}

The physical properties of handsheets made from the 4 passes formulation and recycled cardboard were tested as per TAPPI Method T 220 with a sample cutting pattern shown in Figure 2. All samples were conditioned and tested at room conditions. From TAPPI Method T220 (TAPPI TEST Methods, 1994b), physical testing of pulp handsheets should include mass per unit area (grammage), specific volume, apparent density, tensile strength, stretch, bursting strength, tearing resistance, and MIT folding endurance. Test results are summarised in Table 1. 


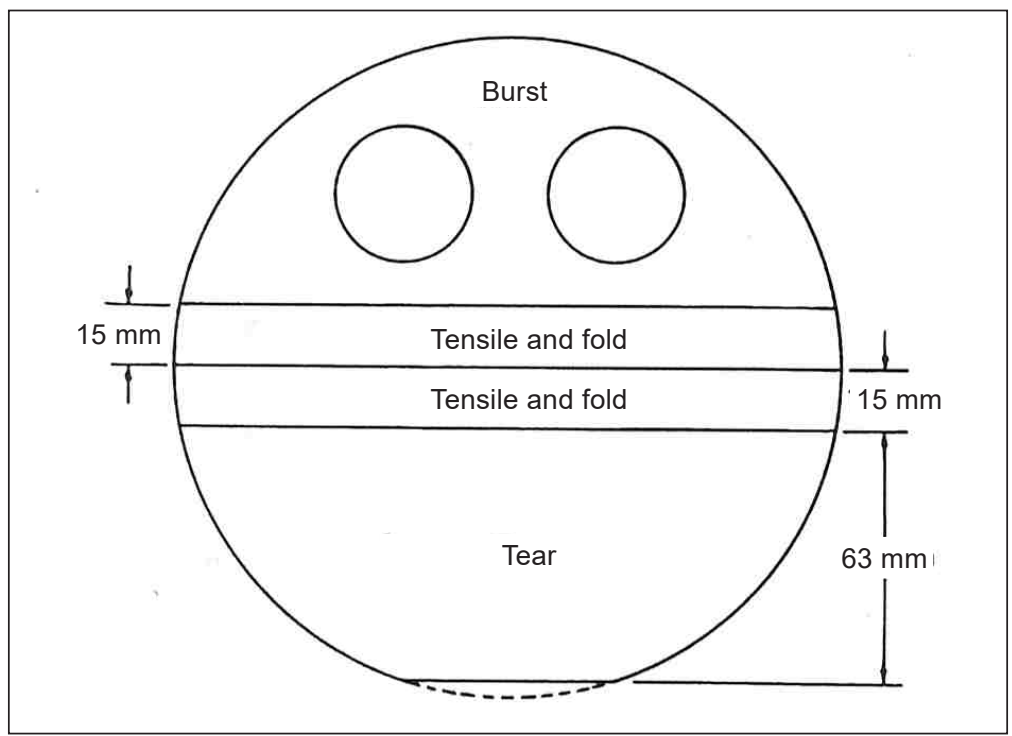

Figure 2. Handsheet cutting pattern

Table 1

Handsheet properties of EFB atmospherically refined

\begin{tabular}{lccc}
\hline Property & $\mathbf{1 0 0 \%}$ EFB 3 Passes & $\mathbf{1 0 0 \%}$ EFB 4 Passes & 100\% Cardboard* \\
\hline Freeness (CSF) & 560 & 420 & 485 \\
\hline Apparent bulk density & 0.25 & 0.49 \\
Specific volume (bulk) & 4.02 & 2.04 \\
Tensile Index & 10.0 & 35.7 \\
Tensile (Breaking Length) m & 1019 & 3637 \\
T.E.A. Index & 131 & 372 \\
Tear Index & 5.3 & 10.4 \\
Burst Index & 0.00 & 1.37 \\
Moisture (\% oven dry weight) & 7.6 & 6.9 \\
Grammage (air dry) g/m ${ }^{2}$ & 63.6 & 62.5 \\
Grammage (oven dry) g/m ${ }^{2}$ & 58.8 & 58.2 \\
\hline
\end{tabular}

*Handsheet made from $100 \%$ recycled cardboard

\section{Freeness of Pulp}

The freeness of pulp is designed to measure the rate at which a dilute suspension of pulp ( $3 \mathrm{~g}$ of pulp in $1 \mathrm{~L}$ of water) may be drained.

The freeness of atmospherically refined EFB fibres and recycled cardboard was tested using the standard Canadian method as per TAPPI Method T227 (TAPPI TEST Methods, 1994c), results were included in Table 1. 


\section{Pulp Moulding}

Pulp moulding product trials were performed using a specially designed laboratory-scale pulp moulding machine. The machine is composed of a control panel, a pulp tank, a set of wet forming moulds, and press moulds. Mould dimensions were approximately 55 $\mathrm{mm}$ deep, $170 \mathrm{~mm}$ long by $140 \mathrm{~mm}$ wide. The process includes wet forming followed by de-watering and drying under elevated temperatures. By controlling the consistency in the pulp tank and the forming/drainage time, the thickness of the resulting punnet can be adjusted. A consistency of between $0.4 \%$ and $0.6 \%$ was used during these trials, and the drying temperature and time adjusted depending on the material, thickness and drainage properties.

\section{RESULTS AND DISCUSSION}

\section{Freeness of Atmospheric Refined EFB}

Empty fruit bunch fibre was successfully refined using a 12" laboratory atmospheric refiner. Throughput became successively smother with each pass as the material became finer and more consistent and thus reduced the tendency to block and clump in the feed screw. Freeness (Canadian standard freeness) was measured after 3 and 4 passes through the refiner and were recorded as 560 and 420, respectively, as shown in Table 1. Freeness is related to the surface conditions and swelling of the fibres (TAPPI method T227, 1994). The higher value of 560 for 3 passes EFB indicated that the pulp is coarser than that of 4 passes EFB at 420.

\section{Properties of Handsheets from Atmospherically Refined EFB}

Handsheets were successfully made from the control sample (100\% recycled cardboard) and EFB pulp with 4 passes in the atmospheric refiner. The freeness of the EFB pulp that had received 3 passes was $560 \mathrm{CSF}$ compared to $485 \mathrm{CSF}$ for the control pulp made from recycled cardboard. It proved difficult to make a handsheet from the 3 pass EFB pulp due to its coarse nature. Physical properties of handsheets are summarised in Table 1. It could be seen that the apparent bulk density of 4 passes EFB fibres was 0.25 , which was about half of the value of the control sample. The low bulk density of EFB fibres resulted in the low values in mechanical properties, for example, Tensile Index at 10 and Tear Index of 5.3; both are much lower than that of control.

\section{Pulp Moulding Trials and Mould Modification}

Initial Pulp Moulding Trial. Trials were carried out on the pulp moulder to make punnets from atmospherically refined EFB fibre. Initial trials with the 4 pass pulp were not satisfactory due to difficulties controlling thickness, fibre distribution and moisture content 
prior to hot pressing. The 3 pass pulp was then blended with the 4 pass pulp at a ratio of 3:7, and with some adjustments to absorbing time, consistency and drainage times, punnets were successfully manufactured. Figure 3 shows the inside and outside of six punnets manufactured from atmospherically refined EFB. The punnet had $12.5 \mathrm{~cm}$ in width, $17 \mathrm{~cm}$ in length and $4 \mathrm{~cm}$ in depth. The appearances of the inside and outside punnet were different due to the setup of the drying process. The inside was smooth, whereas the outside showed the impression of the meshed wire structure.

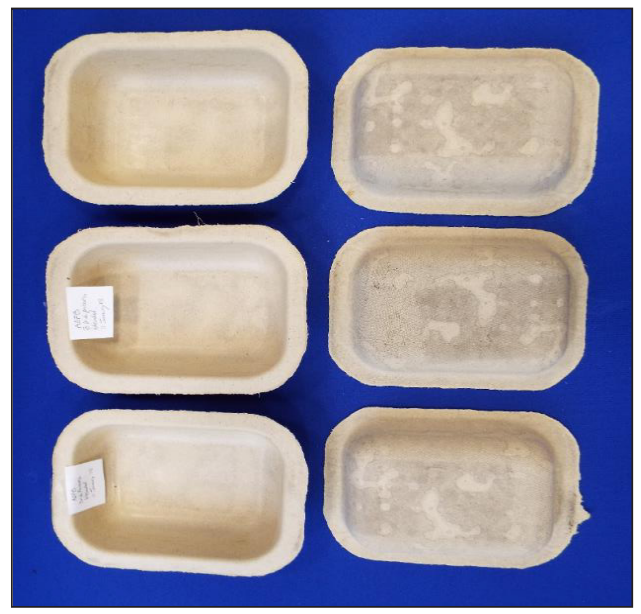

Figure 3. Punnets made from atmospherically refined EFB fibre

Colour differences can be seen in Figure 3. Watermarks caused these due to poor fibre distribution and weak vacuum suction resulting in uneven and excessive water in the punnets prior to hot pressing. If the punnets were too wet going into the hot press, long press times were required to reduce the punnets' tendency to blow apart on the release of the press at the end of the pressing cycle. Pre-drying the punnets (placing them in an oven at $50^{\circ} \mathrm{C}$ overnight) prior to hot pressing significantly reduce the punnets' tendency of to 'blow' apart. However, it did not solve the problem of uneven fibre distribution, which resulted in some punnets having very thin walls-often resulting in holes forming in the punnets on removal from the hot press.

Mould Modification. The initial trials indicated that empty fruit bunch fibre could be refined and pulp moulded into a three-dimensional product. However, the trials brought to light some limitations of the existing laboratory setup and mould configuration. In addition to problems with poor fibre distribution, the mould configuration limitations included: the lack of a rolled and self-trimming lip-important for reducing production time and costs, a lip of suitable dimensions to accept the application of a top seal and a design that would ensure that when the trays are stacked prior to use they can be "de-nested" quickly and do not stick together which is important for production throughput. Therefore, a new mould design with the required features was proposed to solve these issues, as shown in Figure 4 with a digital 3D projection of the expected tray. A new set of moulds were then manufactured and installed (Eco Premium Packaging, Malaysia) onto the existing pulp moulding machine at Bangor University.

With the new design, the mould orientation was changed from the initial concave mould to convex. As shown in Figure 5, the orientation changes were made to improve 
the efficiency of the vacuum suction system, which in turn would help improve the fibre distribution. The addition of a turned edge (rim/flange) means that trimming could be avoided, and the rim should allow for the application of a top seal if required.

Trials were performed using the same formulation and method as described above on the new mould. Punnets were produced successfully without any fibre distribution issues, watermarks also disappeared, and the edges did not require trimming. As shown in Figures 6(a) and (b), smooth surfaces were obtained inside and outside. Punnets were successfully and repeatedly produced, which demonstrated the success of the new moulds in improving the vacuum suction efficiency. Top seal trials were performed within the consortium, and no

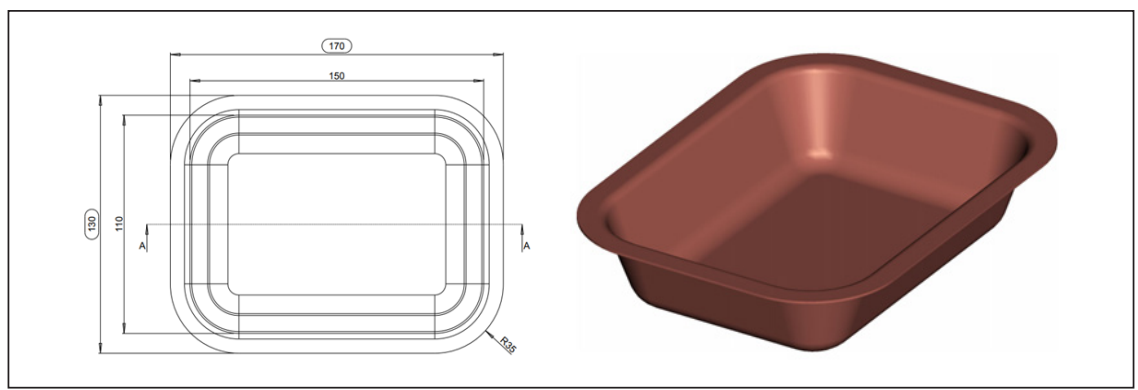

Figure 4. New mould drawing and expected trays

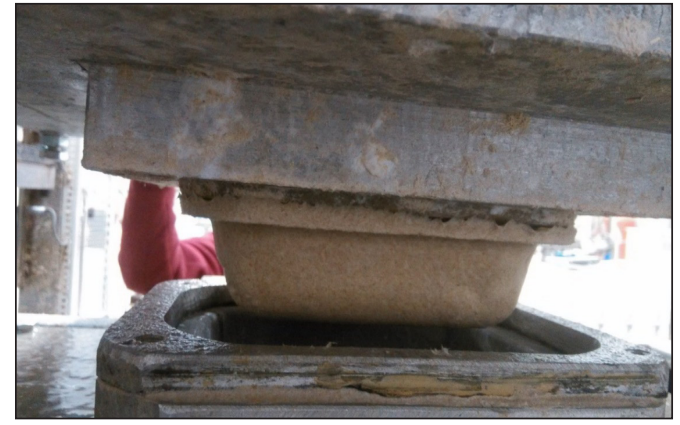

(a)

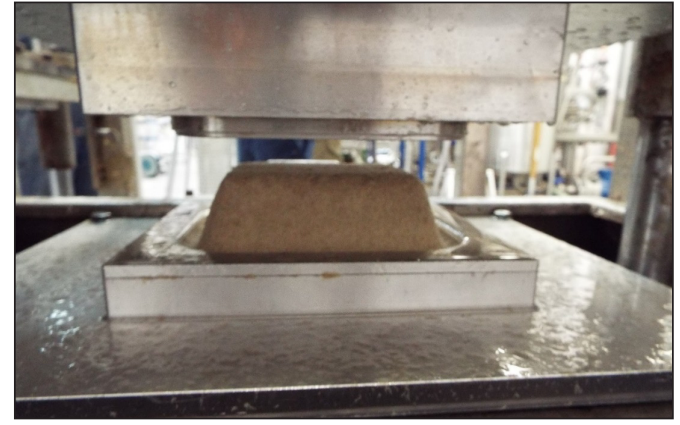

(b)

Figure 5. Current concave forming mould (a) and the new convex forming mould (b)

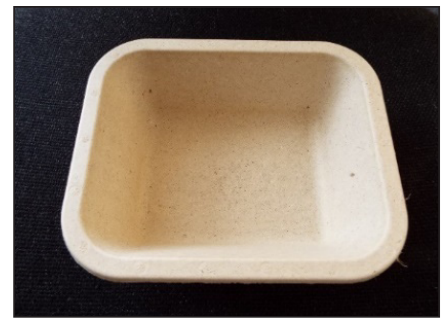

(a)

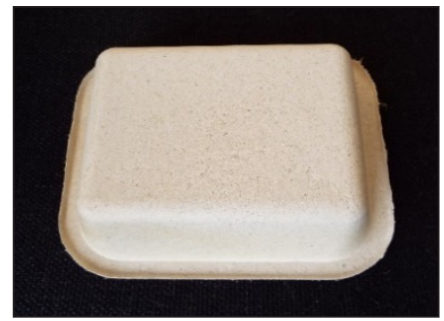

(b)

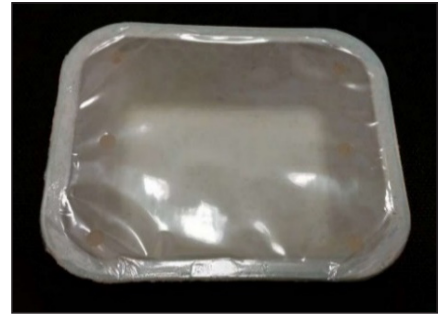

(c)

Figure 6. Punnets made from new mould: (a) Inside; (b) Outside; and (c) Top sealed 
issues were identified when sealing such trays with both fossil-based and bio-compostable lidding films, as shown in Figure 6(c). The results confirmed that it is possible to produce a pulp suitable for making a moulded product by atmospheric refining empty fruit bunch fibre. As atmospheric refining is a mechanical method to break down fibres, no chemicals were needed over the whole pulping processing. The water used in pulp moulding can be easily recycled and reused.

Food interacts with the packaging used to contain it (Munro et al., 2009), so it is important to select packaging that best meets the needs of particular foods (Marsh \& Bugusu, 2007). Further food fill-in testing will be required to understand the interaction between food and EFB pulp moulded trays to bring pulp moulded packaging to the market. Once the food type has been matched to the packaging, marketing is important. Customers are looking for plastic alternatives to food packaging (Guillard et al., 2018) with improved environmental characteristics. Life cycle analysis (to be reported in a further paper) will help provide information on the environmental impact of this package and provide data for marketing.

Importantly food packaging must maintain the quality and safety of food (Geueke et al., 2018) over time and balance different priories not only for the consumer but also for the pre-consumer (food producer, packaging and distribution) and postconsumer (waste recycling/disposal). Therefore, further testing on pulp moulded EFB fibres will demonstrate the suitability and benefits of moulded trays as food packaging. Findings will be reported in the following papers.

\section{CONCLUSION}

The work concluded that, with careful design on moulds, it is possible to produce a pulp suitable for making a pulp moulded product by atmospheric refining empty fruit bunch fibre. As atmospheric refining is a mechanical method to break down fibres, no chemicals were needed over the whole pulping processing. The water used in pulp moulding can be easily recycled and reused. There are obvious environmental benefits to use such refining techniques and agricultural wastes such as EFB for pulp moulding.

While this paper has reported on a method that demonstrates that using a non-wood raw material to make a pulp moulded product is possible, more work is needed before such products find their way into the market. Therefore, the next stage of this project should be to align the properties of this type of packaging material with a food type and then carry out packaging and consumer-based tests and assessments.

\section{ACKNOWLEDGEMENTS}

The authors would like to acknowledge the project funding of Newton-Ungku Omar Coordination Fund: UK-Malaysia Research \& Innovation Bridges Competition 2015 
specific project SafeBioPack (102722). The authors also want to thank all the project partners for their technical support.

\section{REFERENCES}

Bengtström, L. (2014). Chemical identification of contaminants in paper and board food contact materials (PhD Thesis). Technical University of Denmark, Denmark.

Cole, C. (2017, October 20). China bans foreign waste - but what will happen to the world's recycling? The Conversation. https://theconversation.com/china-bans-foreign-waste-but-what-will-happen-to-the-worldsrecycling-85924

Curling, S., Laflin, N., Davies, G., Ormondroyd, G., \& Elias, R. (2017). Feasibility of using straw in a strong, thin, pulp moulded packaging material. Industrial Crops and Products, 97, 395-400. https://doi. org/10.1016/j.indcrop.2016.12.042

Didone, M., Saxena, P., Meijer, E. B., Tosello, G., Bissacco, G., McAloone, T. C., \& Howard, T. J. (2017). Moulded pulp manufacturing: Overview and prospects for the process technology. Packaging Technology and Science, 30(6), 231-249. https://doi.org/10.1002/pts.2289

Ferrer, A., de Vega, A., Ligero, P., \& Rodríguez A. (2011). Pulping of empty fruit bunches (EFB) from the palm oil industry by formic acid. Bioresources, 6(4), 4282-4301.

Geueke, B., Groh, K., \& Muncke, J. (2018). Food packaging in the circular economy: Overview of chemical safety aspects for commonly used materials. Journal of Cleaner Production, 193, 491-505. https://doi. org/10.1016/j.jclepro.2018.05.005

Geyer, R., Jambeck, J. R., \& Law, K. L. (2017). Production, use and fate of all plastics ever made. Science Advance, 3(7), Article e1700782. https://doi.org/10.1126/sciadv.1700782

Grob, K. (2018). Mineral oil hydrocarbons in food: A review. Food Additives \& Contamination: Part A, 35(9), 1845-1860. https://doi.org/10.1080/19440049.2018.1488185

Guillard, V., Gaucel, S., Fornaciari, C., Angellier-Coussy, H., Buche, P., \& Gontard, N. (2018). The next generation of sustainable food packaging to preserve our environment in a circular economy context. Frontiers in Nutrition, 5, Article 121. https://doi.org/10.3389/fnut.2018.00121

Hammett, A. L., Youngs, R. L., Sun, X., \& Chandra, M. (2001). Non-wood fiber as an alternative to wood fiber in chinas pulp and paper industry. Holzforschung, 55(2), 219-224. https://doi.org/10.1515/HF.2001.036

Hamouda, T., Hassanin, A. H., Saba, N., Kilic, M. D. A., Candan, Z., \& Jawaid, M. (2019). Evaluation of mechanical and physical properties of hybrid composites from food packaging and textiles wastes. Journal of Polymers and the Environment, 27, 489-497. https://doi.org/10.1007/s10924-019-01369-3

Hamzah, N., Tokimatsu, K., \& Yoshikama K. (2019). Solid fuel from oil palm biomass residues and municipal solid waste by hydrothermal treatment for electrical power generation in Malaysia: A review. Sustainability, 11(4), 1-23. https://doi.org/10.3390/su11041060

Ibrahim, R., Jasmani, L., Kong, H. W., \& Yusoff, M. N. H. (2007). Commercial-scale production of soda pulp and medium paper from oil palm empty fruit bunches. Journal of Tropical Forest Science, 19(3), 121-126. 
Kibblewhite, R. P., Riddell, M. J. C., \& Shelbourne, C. J. A. (2000). Variation in wood, kraft fibre, and handsheet properties among 29 trees of Eucalyptus regnans, and comparison with E.Nitens and E.Fastigata. New Zealand Journal of Forestry Science, 30(3), 458-474.

Kim, D. S., Sung, Y. J., Kim, C. H., \& Kim, S. B. (2016). Changes in the process efficiency and product properties of pulp mold by application of oil palm efb. Palpu Chongi Gisul. Journal of Korea Technical Association of the Pulp and Paper Industry, 48(1), 67-74. https://doi.org/10.7584/ktappi.2016.48.1.067

Laville, S., \& Smithers, R. (2018, April 26). UK supermarkets launch voluntary pledge to cut plastic packaging. The Guardian. https:/www.theguardian.com/environment/2018/apr/26/uk-supermarkets-launchvoluntary-pledge-to-cut-plastic-packaging

Marsh, K., \& Bugusu, B. (2007). Food packaging - Roles, materials, and environment issues. Journal of Food Science, 72, 39-55

Munro, I. C., Haighton, L. A., Lynch, B. S., \& Tafazoli, S. (2009). Technological challenges of addressing new and more complex migration products from novel food packaging materials. Good Addit Contam Part A Chem Anal Control Expo Risk Assess, 12, 1534-1546.

National Agricultural Library. (2014). Develop a post-market test for recycled food contact materials (Final report: FS241007). U.S. Department of Agriculture.

Or, K. H., Putra, A., \& Selamat, M. Z. (2017). Oil palm empty fruit bunch fibres as sustainable acoustic absorber. Applied Acoustics, 119, 9-15.

Porter, J. (2018, August 12). Wrapper's delight: eco-friendly plastic alternatives. The Caterer. https:/www. thecaterer.com/articles/534918/wrappers-delight-eco-friendly-plastic-alternatives

TAPPI TEST Methods. (1994a). Forming handsheets for physical tests of pulp. TAPPI Press.

TAPPI TEST Methods. (1994b). Physical testing of pulp handsheets. TAPPI Press.

TAPPI TEST Methods. (1994c). Freeness of pulp (Canadian standard method). TAPPI Press.

Taylor, M. (2018, February 28). World's first plastic-free aisle opens in Netherlands supermarket. The Guardian. https://www.theguardian.com/environment/2018/feb/28/worlds-first-plastic-free-aisle-opensin-netherlands-supermarket

UNEP. (2018). Single-use plastics: A roadmap for sustainability. United Nations Environment Programme.

Wever R., \& Twede D. (2007). The history of molded fiber packaging: A 20th century pulp story. In Proceedings of the 23rd IAPRI symposium on packaging (pp. 1-8). Pira International.

Zhaohua, Z., Chunqian, J., Maogong, Z., \& Huafu, W. (1998). Status, trends and prospects for non-wood and recycled fibre in China. Asia-pacific forestry towards 2010. Asia-Pacific Forestry Sector Outlook Study Working Paper Series (FAO). 